\title{
Identification of Fundamental Issues Relevant to Implementing Electronic Health Record Medication Reconciliation: Case of Noor Hospital in Iran
}

\author{
Mona Hemmatboland ${ }^{1}$ \\ ${ }^{1}$ Faculty of Manufacturing and Industrial Engineering, University Technology Malaysia, 81310 UTM Skudai, \\ Johor Bahru, Malaysia \\ Correspondence: Mona Hemmatboland, Faculty of Manufacturing and Industrial Engineering, University \\ Technology Malaysia, 81310 UTM Skudai, Johor Bahru, Malaysia. E-mail: m.hemmatboland@gmail.com
}

Received: August 19, 2019

Accepted: September 9, 2019

Online Published: September 16, 2019

doi:10.5539/ibr.v12n10p11

URL: https://doi.org/10.5539/ibr.v12n10p11

\begin{abstract}
By reviewing in the extant literature, it is inferable that implementation of Electronic Health Record (EHR) is practical for providing salutary effects in the healthcare industries during the procedure of medication reconciliation (Med Rec). This research aims to identify issues or latent concepts relevant to implementing EHR system in the Noor Hospital located in Alborz province, Iran. According to the recent study by scholars, nine latent concepts are related to the implementation of EHR, which are: care coordination issues (CCI); patient education issues (PEI); ownership and accountability issues (OAI); process-of-care issues (PCI); IT-related issues (ITRI); workforce training issues (WTI); workflow issues (WI); resources issues (RI); and documentation issues (DI). The author takes a quantitative method that involves questionnaires distribution among one hundred and thirty-eight practitioners. One hundred and thirty-two valid questionnaires were returned, and collected data were analyzed through the Statistical Package for Social Sciences (SPSS). Findings supported the notion that all issues have a positive relationship with the implementation of EHR Med Rec in the Noor hospital. Among them, DI and PEI had the highest association. The current study implies arresting messages and ramifications for the managers in the healthcare industries in Iran, especially Noor Hospital, and it has its academic benefits in this research era.
\end{abstract}

Keywords: electronic health record, patient outcomes, medication reconciliation, quality management, healthcare industries, Iran

\section{Introduction}

In the tense and stringent competitive era among healthcare industries, especially hospitals, managers and rectorates, should be able to survive their hospitals in order to glean a sustainable competitive advantage based on the formulation of an implementable strategy. There are many felicitous ways to accomplish this, but among them, implementation of EHR in hospitals is one of the auspicious and appropriate ways while breakthrough of information technology in the world. According to the (Marmor, Clay, Millen, Savides, \& Longhurst, 2018), there is a coincidence between emphasizing on patient outcomes and adoption of EHR in hospitals in the USA (Marmor et al., 2018). Therefore, this statement is the chief impetus and arresting for managers in developing countries to follow the USA in this case as a paradigm. Managers who are concerned about the sustainability of their healthcare industries exclusively hospitals should act like perpetual motion machines to derive benefits of EHR implementation of which are practical for both of hospitals and patient outcomes that will be explicated in-depth in the literature review part of this article.

By reviewing the literature by the author of the article, it is explicit that scholars around the world have conducted exemplary studies to uncover myriad advantages of EHR implementation in hospitals including developed and developing countries such as researches by (Boonstra, Versluis, \& Vos, 2014; Darvish \& Far, 2017; Ndifon, Edwards, \& Halawi, 2016; Rangachari et al., 2019; Triantafillou, 2017; Tubaishat, 2019) that will be reviewed comprehensively later. The main ratiocination that lies behind reviewing mentioned researches is that EHR implementation has salubrious effects on the wellbeing of patients and increasing productivity and amelioration of working environment and it has a positive impact on the quality management and its dimensions 
as cited by (Triantafillou, 2017). Another outstanding point is that Iran literature recapitulates studies which not dealing with implementing EHR in the Iranian hospitals as delineated by Darvish and Far (2017) and the author can deduce that dearth of research in this era is unpropitious. Based on the mentioned cogent reasoning, the author has been motivated to conduct a study in the Noor hospital located in the Alborz Province, Iran, which has implemented the EHR System by the end of 2014 in order to the identification of fundamental issues related to EHR Med Rec.

The remainder of this original research paper is followed by firstly, stating the issues related to the problem. Secondly, literature about the advent or emergence of EHR and its functionality in the hospitals, and review of previous researches will be explained. Thirdly, the process of data collection and quantitative method involving questionnaires distribution among practitioners in Noor hospital will be described. Fourthly, collected data from practitioners in the Noor Hospital will be analyzed through SPSS. Lastly, findings will be brought into a discussion. Thenceforth, limitations, implications for managers, and recommendations and avenues for future studies will be explicated.

\subsection{Statement of the Problem}

There have been herculean attempts to diminish medical errors, amelioration of providing high-quality services during care transition in the healthcare industries (Agency for Healthcare Research and Quality, 2016). The compelling reason is that vulnerability and susceptibility of patients to medical errors while medication procedure is usual in the hospital admission and discharge. Medical errors can lead to the adversity of the declining trend of patient outcomes as potent examples of patient safety and satisfaction, and additionally increasing costs affiliated with medication (P. Aspden, J. Wolcott, J. L. Bootman, \& L. R. Cronenwett, 2007; P. Aspden, J. A. Wolcott, J. L. Bootman, \& L. R. Cronenwett, 2007; Mueller, Sponsler, Kripalani, \& Schnipper, 2012). Lack of accessibility to final up-to-date medication information of patients can be detrimental and bring sinuous situations inadvertently to exemplify inadvertent addition, omission, putting patients in perilous or unsafe conditions, or duplicating medications. Mentioned medical errors are unintentional discrepancies between "what patient should be prescribed and what they are actually prescribed"(Burton, 2012; Coleman, 2003a, 2003b; Pronovost et al., 2003). The reason is that the system is not computerized, and they are not keeping updated. To avoid and prevention of medical errors during care transition, advocates of patient outcomes introduced and developed the implementation of EHR Med Rec in hospitals(Barnsteiner, 2005; Greenwald et al., 2010). Adoption of EHR Med Rec is synchronized with the exclusion of paper-based medication process at admission, discharge, or both of them(Grossman, Gourevitch, \& Cross, 2014). It is lucid that the implementation of the EHR project is beneficial, and its merits outweigh its defects. Based on the nature of each project, there are vital issues related to EHR as proposed by Rangachari et al. (2019) to evaluate conception and understanding from practitioners perspectives working in the hospital because due to lack of misunderstanding of fundamental issues; problems will be subsequent. Therefore, this research aims to find out critical issues related to EHR Med Rec in the Noor hospital which has implemented the EHR project from admission to discharge in order to the alleviation of medication discrepancies during medication procedure, achievement, and improvement of the high level of data accuracy in the patient medication list.

\section{Literature Review}

\subsection{The Emergence of EHR and Its Functionality}

In the viewpoint of historical perspective, the emergence of EHR traces back approximately sixty years ago around the 1960s in the USA in one form or another (Versel, 2013). EHR can be described as a digital or computerized record of medication process of a client from admission to discharge which is kept and maintained in the hospital or offices of doctors, and recorded information can be shared among healthcare services such as hospitals, medical agencies, and doctors(Ndifon et al., 2016). The principal idea that lies behind the implementation of EHR in the USA was to create a web-based National Health Information network concurrently protection of privacy and personal information related to the health of clients(Ndifon et al., 2016). It is essential to state that the implementation of EHR in the USA was according to the three premises, which were; 1 . Results of the myriad studies that support saving lives and money through electronic healthcare. 2. Advantages of electronic healthcare outweigh its costs, and it can be beneficial. 3. The trend of demand for electronic healthcare was considerable (Ndifon et al., 2016). In another study by Gonzalez (2013), the outstanding merits of national EHR technology are inclusive of "care continuum, reduction in costs, managing medications, long-term strategic point of view and portability, emergency episode management and empowering patients." The inception of proposing implementing EHR in hospitals in Organization for Economic Cooperation and Development (OECD) countries traces back virtually 1990s (Triantafillou, 2017). To highlight implementing 
EHR and benefits associated with it, Nguyen, Bellucci, and Nguyen (2014) conducted a systematic literature review paper regarding EHR implementation in the hospital around the world. As noted by the Handbook for EHR implementation, key functionalities of EHR are delineated as follows: "1. Storing and retrieving health information and data 2. Management of findings 3. Order/entry management 4. Strategic decision making and managing support 5. Electronic communication and connectivity 6. Corroborating patients 7. Administrative procedures 8. Reporting and population health (Handbook for EHR implementation, p.18)." By reviewing the above literature, the author can infer that EHR implementation is advantageous, and it can function as a strategy for managers to husband resources in the long-term.

\subsection{Review of Expedient Studies by Previous Scholars}

Boonstra et al. (2014) conducted sound research in order to the creation of a comprehensive overview regarding extant literature related to the implementation of EHR in hospitals. As noted by Boonstra et al. (2014), there is diversity referring to this subject. Therefore, to glean accurate and sound findings Boonstra et al. (2014) applied a Systematic Literature Review (SLR) and multifarious academic databases such as EBSCO, Web of Knowledge and Cochrane library were searched and among 364 articles of which were downloaded at the first stage, 21 articles were considerable due to fulfilling the requirement of the study. It is consequential to state that after reviewing articles, Boonstra et al. (2014) proposed a theoretical framework that consists of 3 interacting dimensions, which are "EHR context, EHR content, and EHR implementation process." These mentioned dimensions have general applicability regarding the implementation of EHR in Hospitals. Boonstra et al. (2014) concluded that implementers of EHR in hospitals could benefit from the proposed framework, and it can have superior functionality to be as a reference for managers who have the plan to implement EHR in hospitals.

Ndifon et al. (2016) conducted a study in the United States of America (USA) to evaluate the effect of EHR since 2009. As stated by Ndifon et al. (2016), the prevalence of EHR and attraction, and its adoption have been considerable since 2009, which was the HITECH Act year. Thus, this study assesses the adoption of EHR in the USA and its determination on patient outcomes. Utilizing the qualitative approach to identify the effect of EHR on patient outcomes and secondary data while some empirical data were represented based on searching in various databases. Results of this research supported that EHR has a profound effect on "clinical outcomes, patient perception and satisfaction, hospital readmissions, patient monitoring, and compliance, and patient safety" as cited by (Ndifon et al., 2016). The originality and value of this research have been commendable in the USA due to lack of published articles in this research era while there are some limitations within this study which are inadequacies or shortages of empirical investigations researches those are based on data analyses (Ndifon et al., 2016).

Darvish and Far (2017) conducted a study with the primary aim of exploring Iran literature about electronic health. Authors took searching in academic databases as the method of the research. Therefore, sound sources such as PubMed, Google Scholar, Science Direct, Magiran, SID, and Irandac were considered to achieve a comprehensive list of articles for further investigation. Duration of published articles was between September 2005 and April 2016. Approximately seventy-four published papers were selected, and among them, 40 of them were chosen according to their expediency to the research by (Darvish \& Far, 2017). Findings indicated that there are some fundamental problems such as managerial, technical, social, and obstacles within organizations in Iran in order to implement EHR technology in healthcare industries. It is substantial to assert that as delineated in Iran literature, implementation of EHR is the pragmatic and productive way to enhance the level of the healthcare system in Iran and its practicality to improve healthcare in Iran is irrefutable (Darvish \& Far, 2017).

Tubaishat (2019) researched Jordanian hospitals to explore the impact of EHR on patient safety from the nurses' perspectives. The author took a qualitative method inclusive of semi-structured interviews with 17 nurses who were staff in Jordanian hospitals. It is worthwhile mentioning that nurses have 1-5 years' experience working with EHR systems. According to the thematic analyses elicited from the interviews, results of the research by Tubaishat (2019) revealed that increasing the level of patient safety by EHR system while diminishing medication errors, upgrading data documentation, increasing level of data completeness, and developing data sustainability. One remarkable point stated by nurses is that poor EHR system leads to jeopardizing patient safety. These problems arise from errors during entering data, problematic technical issues, minimal clinical alerts, and poor use of system communication channels. Thus, nurses asserted that engagement of practitioners with new design and specification is mandatory in order to eliminate such mentioned problems (Tubaishat, 2019).

Rangachari et al. (2019) researched AU Health located in Augusta, Georgia, with the purpose of identification of all categories relevant to EHR Med Rec in order to essay for diminution of discrepancies during medication procedure. To achieve the aim of the study, they took a mixed-method, which is a combination of qualitative and 
quantitative methods. Thus, the research design was based on the exploratory mixed method of which was a felicitous way for data gathering and then analytical procedure according to the Creswell (2014) as cited by (Rangachari et al., 2019). It is noteworthy to state that respondents were practitioners inclusive of physicians, nurses, and pharmacists of which were 215 practitioners. For further clarification, for the qualitative method, 15 practitioners with sufficient expertise were interviewed and base on the results of interviews and voice recording during thematic analysis, a questionnaire was proposed by the authors. It is worthwhile mentioning that output of interviews was an indication of 9 issues or latent concepts expedient to EHR Med Rec which are "CCI, PEI, OAI, PCI, ITRI, WTI, WI, RI, and DI.” There is another salient point to take into consideration that the questionnaire involves 55 items or questions. Questionnaires were distributed among participants, and from 200 distributed ones, 127 complete and accurate were retrieved, and it was adequate for initiation of data processing. For the case of data analysis, the authors utilized STATA 14 software and descriptive statistics for demographic variables, factor analysis, reliability test, and analysis of variance (ANOVA) were performed. Results supported the notion that after conducting factor analysis and reliability tests, three issues among nine issues were excluded, which were DI, RI, and WI. Findings delineated that there are challenges regarding implementation of EHR Med Rec system in the cases of clinical transitions of care, difficulties stemming from interacting practitioners with the EHR technology, and problematic situations related to sociotechnical issues. The reviewed research was pragmatic in the case of contribution to this research era because of introducing a well-qualified survey instrument in order to the measurement of each issue relevant to EHR. Bringing insight and suggestion of strategies in line with shared conception and recognition of the value of EHR Med Rec and additionally addressing challenges related to sociotechnical matters via workflow and system redesign through engaging practitioner/stakeholder of which will be appropriate strategies for efficient use of implementing EHR Med Rec technology in the healthcare industries.

\subsection{EHR and Quality Management}

Triantafillou (2017) conducted a study to concede a narrative review of extant researches to determine and bringing into discussion bolstering quality management and its three dimensions through EHR implementation. The research methodology was based on academic literature and searching in various valid databases such as Web of Science, EBSCO, Scopus, and others. As cited by Triantafillou (2017), quality management is a function of three dimensions, which are clinical outcomes, managerial monitoring, and cost-effectiveness. Results of the review of 39 types of research revealed that 29 studies supported the clinical outcomes. Virtually, 36 studies are an indication of the capability of EHR to increase managerial monitoring of clinical activities. And among 39 studies, exclusively, five of them supported the relationship with EHR and cost-effectiveness (Triantafillou, 2017). Majority of the studies supported the notion that EHR has a positive effect on quality management and its dimensions (Triantafillou, 2017).

\subsection{Conclusion of Review in Literature and EHR in Iran}

By reviewing the above literature, it can be deduced that EHR implementation in hospitals has attracted researchers' attention in different countries inclusive of developed and developing ones. Besides, referring to the Iran literature in this era, Iran literature recapitulates that scholars have pursued advanced studies for unearthing myriad instances in the era of electronic health in the Iranian hospitals. For exemplification, conducted studies in Iran by (Borhani, Lashkari, Sabzevari, \& Abbaszadeh, 2013; Maslakpak \& Safaie, 2016; Vakili, Abedi, Afshari, \& Kaboli, 2015) deal with telephone or mobile health monitoring. Conducted studies in Iran by (Ajami, Ketabi, Isfahani, \& Heidari, 2011; Nasiripour, Rahmani, Radfar, \& Najafbeigi, 2012; Salehahmadi \& Hajialiasghari, 2013) deal with electronic health and implementation of telemedicine. Conducted studies in Iran by (Farahani, Sharifi, Ayat, \& Moghaddam, 2014; Hekmat et al., 2016; Jahanbakhsh, Sharifi, \& Ayat, 2014)deal with information systems and web-based training in the hospitals.

The conclusion is that: firstly, by taking into consideration above reviewed studies in other countries. Secondly, exemplifying researches which have done in the era of electronic health in Iran as categorized earlier and noted by (Darvish \& Far, 2017). Thirdly, the importance of managerial issues in the healthcare industries in Iran, author of this article can infer that no study to date has addressed identifying issues related to EHR Med Rec in Iran, especially within the defined scope of current research. Thus, earlier contention has been an inducement for the author of a present scientific article to conduct a study with the purpose of identification of relevant issues to EHR Med Rec in the Noor hospital situated in Alborz province, Iran to contribute to the body of existing knowledge. 


\section{Research Methodology}

\subsection{Data Collection Procedure and Respondents}

Data was collected by the author of the article who had sufficient experience about the content of the standard survey questionnaire and was disinterested about the procedure of fieldwork. First of all, since the original version of scales were in the English language, the author translated into the Persian language and converted one was reviewed by an external reviewer who had expertise in this field. Thenceforth, amendments and modifications were made, and permission regarding questionnaires distribution among practitioners in the Noor hospital was obtained from the Managing Director before the initiation of data collection. In total, one hundred and thirty-eight practitioners are employed in the hospital inclusive of the optometrist $(\mathrm{N}=17)$, nursing $(\mathrm{N}=14)$, Operation Room (OR) staff ( $N=29)$, OR secretary $(\mathrm{N}=2)$, ward secretary $(\mathrm{N}=1)$, admission staff $(\mathrm{N}=6)$, discharge staff $(\mathrm{N}=3)$, IT staff $(\mathrm{N}=1)$, the ophthalmologist $(\mathrm{N}=42)$, and other related categories. Among distributed questionnaires, one hundred and thirty-two valid copies with the response rate of 95.6 percent were retrieved and were reliable and sufficient for data analysis. Questionnaires were distributed with simple random sampling to make sure there is no bias to collect valid and reliable data and each person in the target population has an equality for being selected (William Zikmund \& Babin, 2006; WG Zikmund \& Babin, 2009; W. G. Zikmund, Babin, Carr, \& Griffin, 2013).

\subsection{Questionnaire Development}

The designing questionnaire in the current study is based on scales introduced by Rangachari et al. (2019) for each latent construct as represented in table 1. As mentioned earlier in the literature review of this article, Rangachari et al. (2019) proposed nine issues related to EHR Med Rec of which is inclusive of 55 items. All items were rated on a 5-point Likert scale that is intensifying labeling (1= Unimportant, $2=$ Extremely unimportant, 3= Average, 4= Important, 5= Extremely Important). Table 1 contains information relevant to each latent construct and defined codes.

Table 1. Measurement Items

\begin{tabular}{ccc}
\hline Latent Construct & No. of Items & Code and Supporting Reference \\
\hline$(\mathrm{CCI})$ & 7 & CCI-1-CCI-7 Rangachari et al. (2019) \\
$(\mathrm{PEI})$ & 9 & PEI-1-PEI-9 Rangachari et al. (2019) \\
$(\mathrm{OAI})$ & 10 & OAI-1-OAI-10 Rangachari et al. (2019) \\
$(\mathrm{PCI})$ & 6 & PCI-1-PCI-6 Rangachari et al. (2019) \\
$(\mathrm{ITRI})$ & 9 & ITRI-1-ITRI-9 Rangachari et al. (2019) \\
$(\mathrm{WTI})$ & 6 & WTI-1-WTI-6 Rangachari et al. (2019) \\
$(\mathrm{WI})$ & 3 & WI-1-WI-3 Rangachari et al. (2019) \\
$(\mathrm{RI})$ & 3 & RI-1-RI3 Rangachari et al. (2019) \\
$(\mathrm{DI})$ & 2 & DI-1-DI-2 Rangachari et al. (2019) \\
\hline
\end{tabular}

\section{Data Processing and Findings}

\subsection{Reliability Test}

Reliability tests were performed to check internal consistency among items of the questionnaire after completion of data gathering. Conducting a reliability test was done for each latent construct separately, and the procedure was interchangeable for each latent construct as represented in table 1 . Thenceforth, a reliability test was run for all items, including fifty-five (55) questions of the questionnaire. According to the research by Cronbach (1951), the value of Cronbach's alpha should meet the level of above 0.6 for exploratory investigations. As cited by Gefen, Straub, and Boudreau (2000) which is a highly cited article, the value of Cronbach's alpha should fulfill the level of above 0.7 for confirmatory researches according to the assertions of previous studies (Nunnally, 1978; Nunnally \& Bernstein, 1967; Peter, 1979). The current research is confirmatory because the scale of latent constructs have been adapted from a former study by Rangachari et al. (2019) and proposed survey instrument has been implemented in the Noor hospital located in Iran as described earlier. Results of reliability analyses supported sufficient internal consistency among questions for each construct and also all items. Table 2 represents the findings of reliability analyses of which are indications of the reliability of current research to proceed. 
Table 2. Results of Reliability Tests

\begin{tabular}{ccc}
\hline Latent Construct & No. of Items & Value of Cronbach's alpha \\
\hline All Items of Questionnaire & 55 & .928 \\
(CCI) & 7 & .908 \\
(PEI) & 9 & .944 \\
(OAI) & 10 & .925 \\
(PCI) & 6 & .739 \\
(ITRI) & 9 & .747 \\
(WTI) & 6 & .736 \\
(WI) & 3 & .911 \\
(RI) & 3 & .742 \\
(DI) & 2 & .946 \\
\hline
\end{tabular}

\subsection{Factor Analysis}

Factor analysis is a robust technique to check the validation of data set, normality of collected data, and testing suitability of matrix for factorability (Coakes \& Steed, 2009). For the testing data set, factor analysis with principal component analysis (PCA) extraction method with varimax rotation was performed for all fifty-five items. Based on notes by Coakes and Steed (2009), when myriad correlations in the correlation matrix are above the threshold of .3; it is an indication of the suitability of the pattern for factorability of which this statement is entirely acceptable for the performed factor analysis by the author of this research. Reliability of factor analysis is dependent on the size of the sample, and for running factor analysis, the sample size of more than one hundred is suggested (Field, 2005). It is worthwhile stating that based on KMO and Bartlett's test, Kaiser Meyer-Olkin Measure of Sampling Adequacy (KMO-MSA) should be above 0.6 (Kaiser, 1974). The result of KMO- MSA in this research is .772, and also Bartlett's Test of Sphericity is considerable and has a finding of 8888.169 with the 1485 degree of freedom at the significance level of less than .001 recommended by (Bartlett, 1954). Table 3 delineates expedient information. For further interpretation, communality item should exceed 0.5 for each item of extraction as noted by Hair, Sarstedt, Ringle, and Mena (2012), and factor loading for each item should be above 0.4 (Churchill Jr, 1979). Results are distinctive emblems of acceptable findings for each item related to communality and also factor loading. According to the rotated component matrix, all variance/ loading is above the 0.4 and meet the thresholds. Therefore, the author of this study can elicit that no item should be excluded at this stage of data processing. Thenceforth, author computed an average for each latent construct for the remainder of data processing. Table 4 limns information relevant to factor loading and extraction of communality for each item.

Table 3. KMO and Bartlett's Test

\begin{tabular}{llr}
\hline Kaiser-Meyer-Olkin Measure of Sampling Adequacy. & .772 \\
\hline Bartlett's Test of Sphericity & Approx. Chi-Square & 8888.169 \\
\cline { 2 - 3 } & $\mathrm{df}$ & 1485 \\
& Sig. & .000 \\
\hline
\end{tabular}

Table 4. Communalities Extraction and Factor Loadings based on Rotated Component Matrix

\begin{tabular}{|c|c|c|}
\hline Factors Adapted from Rangachari et al. (2019) & $\begin{array}{c}\text { Factor } \\
\text { Loading }\end{array}$ & $\begin{array}{l}\text { Extraction of } \\
\text { Communality }\end{array}$ \\
\hline $\begin{array}{l}\text { CCI1: "The medication list is not complete when the patient returns to the } \\
\text { clinic after being discharged from the hospital (even if the system shows } \\
\text { discharge reconciliation as full)." }\end{array}$ & .847 & .863 \\
\hline $\begin{array}{l}\text { CCI2: "The current process of "discharge-then-pharmacy scripts" rushes the } \\
\text { process, making it difficult for the pharmacy to meet patients as they transition } \\
\text { into the community. Several opportunities for patient education (e.g., } \\
\text { affordable options for drug substitutes) are missed, as a result." }\end{array}$ & .864 & .876 \\
\hline $\begin{array}{l}\text { CCI3: "No arrangements have been made for post-discharge follow-up with the } \\
\text { patient's clinic to monitor interactions of new medicines with the patient's } \\
\text { existing medication." }\end{array}$ & .830 & .885 \\
\hline
\end{tabular}


CCI4: "Good medication management in the hospital alone is not sufficient. Patients are not in control after they have transitioned to the community or their usual, customary care, which, in turn, creates the risk for readmission."

CCI5: "Sometimes, chronic disease polypharmacy patients on 15 or more medications do not have a primary care physician designated in the system."

CCI6: "We do not have a process in place for identifying people who do not have a primary care physician in our EHR, and designating one from within our health system, to ensure care coordination."

CCI7: "Some patients may have multiple pharmacies and multiple subspecialist physicians. This is a challenge since we currently do not have a reliable interface between pharmacies, specialty clinics, and primary care clinics."

PEI1: "Patients do not understand when they need to stop taking a previous prescription and start taking the updated one."

PEI2: "Patient insurance issues are not addressed at discharge."

PEI3: "Patients are not educated to take control of their medication management following discharge."

PEI4: "Often, patients do not have their medication lists or pill bottles with them, which makes it difficult to verify what they are actually taking."

PEI5: "Patients need to understand why they are taking each drug, e.g., infection drug, the diabetes drug, and BP drug, to ensure that they stick with the regimen. This is an area for improvement."

PEI6: "We do not have a standardized system for educating patients that they need to bring in their pill bottles each time they visit the clinic or ED."

PEI7: "We do not have a user-friendly form or template for patients/families to list their medications while they are waiting to be seen."

PEI8: "Patients are not receiving discharge instructions on which medicines to continue taking, which to stop, and why."

PEI9: "Sometimes, patients end up taking both an earlier prescription and a replacement prescription since they have not been properly educated."

OAI1: "Since several practitioner groups are involved in medication reconciliation, without a shared understanding of each other's responsibilities, multiple medication lists (with varying drug information) exist for a single patient, instead of a master list."

OAI2: "There is no provision to indicate the patient is "not taking" medication on the active medication list. Nurses' documentation of "not taking" in the medical record may be missed by the doctor, which in turn, may prevent meds from being discontinued in a timely fashion."

OAI3: "A patient may have a $\beta$-blocker drug that is on hospital formulary ordered, to replace the home $\beta$-blocker drug, during the hospital stay, but the former may not be discontinued at discharge, allowing both formulary and home (i.e., duplicate) prescriptions of the $\beta$-blocker to be continued on the patient's active medication list."

OAI4: "Doctors generally prefer not to discontinue a medication from the list, if they did not originally order it, or are unfamiliar with the drugs in question."

OAI5: "At the study institution, pharmacy technicians are not being utilized to collect medication history in the ED, prior to admission, even for polypharmacy patients."

OAI6: "Medication reconciliation has not been heavily emphasized for nursing, so the responsibility falls upon all groups involved in patient care delivery to capture medication history."

OAI7: "Medication reconciliation is not as heavily emphasized for subspecialists as it is for primary care physicians."

OAI8: "In some instances, hospital personnel who notice their peers inputting incorrect information also take time to report them, which could become a cycle of blame-shifting."

OAI9: "Sometimes, patients experience frustration toward hospital personnel, since their medication list, which they are asked about multiple times, is not viewable by all hospital personnel."

OAI10: "The quality of medication information captured varies between triage providers, hospitalists, and nurses on the floor."

PCI1: "We do not have processes in place to ensure comprehensive medication history at the front end (admission), which makes it difficult for medication reconciliation to be completed at the back end (discharge)."

PCI2: "Both on the outpatient and inpatient sides, the process of obtaining medication history from pharmacies and primary care physicians is 
PCI3: "Patients may not always be aware of the medications they are on, making the process of compiling a complete and accurate medication list, a challenging one for hospital providers."

PCI4: "Medication reconciliation is performed only at admission and discharge, and not during the hospital stay, to supplement data gathered at admission, which in turn, affects the accuracy of reconciliation at discharge."

PCI5: "During the hospital stay, patients are not in regular contact with pharmacists, who are in the best position to update patients' medication history and the active medication list."

PCI6: "The medication list needs to be dynamic, not static. Often, the admission H\&P is not amended while the patient is in the hospital, even if new information is provided by the patient/family."

ITRI1: "Some of our patients have primary care physicians outside of our system, and we are often unable to access their medication reconciliation on the EHR."”

ITRI2: "Patients are portable. However, even within our local community, there are many hospital EHRs that are not accessible to physicians in our system."

ITRI3: "While we can retrieve external $\mathrm{Rx}$ histories from various local pharmacies through the EHR, the medication history from our outpatient pharmacy is not retrievable on the EHR."

ITRI4: "Our EHR system does not include enough clinical decision support for clinical guidelines like core measures, although we do have support for drug allergy alerts and drug-to-drug interactions."

ITRI5: "For statin prescriptions (among MI patients), the medication label automatically prints out that it is "for cholesterol," which may be confusing for patients who do not have cholesterol."

ITRI6: "Sometimes on the EHR, orders for certain medications tend to prepopulate the dosages inaccurately, e.g., valium and vitamin D."

ITRI7: "The EHR is reasonably slow. Some controlled substances cannot be printed in the same room, so providers need to go to a different room, which can slow things down."

ITRI8: "A checkbox against discharge medication reconciliation does not mean it is done. Providers understand that the button needs to be checked to bill for the patient, but they also know that the discharge medication list may be inaccurate or incomplete."

ITRI9: "Users of the software system need to figure out how they can work with the configurations within the EHR system, as opposed to "working around" or against it."

WTI1: "Oftentimes, house staff does not understand the importance of comprehensively documenting the medication history and continuously updating the medication list, to facilitate smooth discharge and prevent readmissions."

WTI2: "The importance of medication reconciliation needs to be emphasized during resident orientation and training."

WTI3: "Pharmacists could play a key role in educating hospital residents on selecting the right drug and dose; improving drug documentation and identifying substitutes when patients cannot afford the drugs prescribed. This is an area for improvement."

WTI4: "Medical assistants, who are responsible for taking the medication inventory and entering it in the system, may not have had any pharmacological training."

WTI5: "Medical assistants in orthopedics may be completely unfamiliar with cardiac medications. For example, in orthopedics, they dose medicines in pounds, whereas in cardiology, they are dosed in kilograms."

WTI6: "Nursing personnel needs training on how to effectively utilize limited time and resources to gather medication history to improve the workflow, rather than lose time working against the system."

WI1: "When our ED or clinics are busy, medication history is not being obtained and recorded comprehensively."

WI2: "For attending physicians, logging back into the computer to approve the final medication list after the nurse has prepared it can produce a delay, which can create a backlog of patients on a busy day."

WI3: "Due to time constraints, especially during triage, medication reconciliation becomes a heavy burden on providers rushing to help the next patient; this often leads to incomplete and inaccurate information for medications inputted into the EHR." 
RI1: "In the ED, nurses are already stretched with documentation responsibility, so some form of supplemental staffing (e.g., pharmacy techs) may be necessary for medication history."

RI2: "On the outpatient side, medication reconciliation proceeds smoothly when nurses have the time and resources; they need to complete medication history."

RI3: "On the inpatient side, if a patient is incapacitated, we do not have a provision to leverage patient navigators in obtaining medication histories by engaging families during the hospital stay."

DI1: "The specific details related to medications names, types, and dosages are not well-documented on the discharge medication list. For example, "sustained release" vs. "controlled release" dosing is not documented well."

DI2: "Primary care physicians should prepare the medication list from scratch, each time the patient changes care, by documenting the whole list. The physician's notes, in turn, should provide information on the patient's updated medication list to all other providers of care. This is an area for improvement."

Extraction Method: Principal Component Analysis. Rotation method: Varimax with Kaiser Normalization. Rotation converged in eight (8) iterations.

\subsection{Correlation Analyses among Latent Concepts}

Referring to the recent research by Rangachari et al. (2019), and as depicted in tables 1 and 2 of this scientific article; there are nine latent constructs of which are relevant to implementing EHR. Each of this latent construct is a latent concept, and its definition stands on its concept. Thus, after data gathering, the correlation among these latent concepts should be examined to test the association between each pairwise of them. R-value, which is an indication for representing the relationship among two variables ranges from -1 to +1 . Relationship between each pairwise variables should not exceed above $\mathrm{R}=0.95$ because correlation more than this measure will lead to collinearity, and for the $\mathrm{R}=1$, the singularity will occur (Kline, 1998). According to the findings of correlation analyses among nine latent constructs in this research, there is no relationship above the level of 0.95 , and this is a sign of the understanding of nine different concepts by respondents in the Noor hospital located in Alborz Province, Iran. Table 5 contains correlations among latent concepts at the significance level of 0.01 and 0.05. As can be seen in table 5, the highest positive relationship is between PEI and CCI that is R equal with .737 less than .95 .

Table 5. Correlations among Latent Constructs

\begin{tabular}{|c|c|c|c|c|c|c|c|c|c|c|}
\hline & & $\mathrm{CCI}$ & PEI & OAI & PCI & ITRI & WTI & WI & RI & DI \\
\hline \multirow[t]{3}{*}{$\mathrm{CCI}$} & $\begin{array}{l}\text { Pearson } \\
\text { Correlation }\end{array}$ & 1 & $.737^{* *}$ & $.568^{* * *}$ & $.268^{* * *}$ & $.296^{* *}$ & $.649^{* * *}$ & .068 & -.056 & .009 \\
\hline & Sig. (1-tailed) & & .000 & .000 & .001 & .000 & .000 & .218 & .262 & .460 \\
\hline & $\mathrm{N}$ & 132 & 132 & 132 & 132 & 132 & 132 & 132 & 132 & 132 \\
\hline \multirow[t]{3}{*}{ PEI } & $\begin{array}{l}\text { Pearson } \\
\text { Correlation }\end{array}$ & $.737^{* *}$ & 1 & $.731^{* *}$ & .085 & $.179^{*}$ & $.339^{* *}$ & .075 & -.043 & -.039 \\
\hline & Sig. (1-tailed) & .000 & & .000 & .165 & .020 & .000 & .198 & .313 & .329 \\
\hline & $\mathrm{N}$ & 132 & 132 & 132 & 132 & 132 & 132 & 132 & 132 & 132 \\
\hline \multirow[t]{3}{*}{ OAI } & $\begin{array}{l}\text { Pearson } \\
\text { Correlation }\end{array}$ & $.568^{* * *}$ & $.731^{* *}$ & 1 & .063 & $.231^{* *}$ & $.322^{* *}$ & .018 & .000 & -.105 \\
\hline & Sig. (1-tailed) & .000 & .000 & & .236 & .004 & .000 & .419 & .498 & .115 \\
\hline & $\mathrm{N}$ & 132 & 132 & 132 & 132 & 132 & 132 & 132 & 132 & 132 \\
\hline \multirow[t]{3}{*}{ PCI } & $\begin{array}{l}\text { Pearson } \\
\text { Correlation }\end{array}$ & $.268^{* * *}$ & .085 & .063 & 1 & $.416^{* *}$ & $.403^{* *}$ & -.076 & .079 & -.021 \\
\hline & Sig. (1-tailed) & .001 & .165 & .236 & & .000 & .000 & .192 & .183 & .407 \\
\hline & $\mathrm{N}$ & 132 & 132 & 132 & 132 & 132 & 132 & 132 & 132 & 132 \\
\hline \multirow[t]{3}{*}{ ITRI } & $\begin{array}{l}\text { Pearson } \\
\text { Correlation }\end{array}$ & $.296^{* *}$ & $.179^{*}$ & $.231^{* *}$ & $.416^{* *}$ & 1 & $.584^{* *}$ & $-.149^{*}$ & $.495^{* *}$ & -.051 \\
\hline & Sig. (1-tailed) & .000 & .020 & .004 & .000 & & .000 & .044 & .000 & .282 \\
\hline & $\mathrm{N}$ & 132 & 132 & 132 & 132 & 132 & 132 & 132 & 132 & 132 \\
\hline \multirow[t]{3}{*}{ WTI } & $\begin{array}{l}\text { Pearson } \\
\text { Correlation }\end{array}$ & $.649^{* *}$ & $.339^{* *}$ & $.322^{* *}$ & $.403^{* *}$ & $.584^{* *}$ & 1 & -.141 & $.414^{* *}$ & -.074 \\
\hline & Sig. (1-tailed) & .000 & .000 & .000 & .000 & .000 & & .053 & .000 & .199 \\
\hline & $\mathrm{N}$ & 132 & 132 & 132 & 132 & 132 & 132 & 132 & 132 & 132 \\
\hline \multirow{2}{*}{ WI } & $\begin{array}{l}\text { Pearson } \\
\text { Correlation }\end{array}$ & .068 & .075 & .018 & -.076 & $-.149^{*}$ & -.141 & 1 & -.109 & -.030 \\
\hline & Sig. (1-tailed) & .218 & .198 & .419 & .192 & .044 & .053 & & .108 & .365 \\
\hline
\end{tabular}




\begin{tabular}{|c|c|c|c|c|c|c|c|c|c|c|}
\hline \multirow[b]{2}{*}{ RI } & $\mathrm{N}$ & 132 & 132 & 132 & 132 & 132 & 132 & 132 & 132 & 132 \\
\hline & $\begin{array}{l}\text { Pearson } \\
\text { Correlation }\end{array}$ & -.056 & -.043 & .000 & .079 & $.495^{* *}$ & $.414^{* *}$ & -.109 & 1 & $-.157^{*}$ \\
\hline \multirow{5}{*}{ DI } & Sig. (1-tailed) & .262 & .313 & .498 & .183 & .000 & .000 & .108 & & .036 \\
\hline & $\mathrm{N}$ & 132 & 132 & 132 & 132 & 132 & 132 & 132 & 132 & 132 \\
\hline & $\begin{array}{l}\text { Pearson } \\
\text { Correlation }\end{array}$ & .009 & -.039 & -.105 & -.021 & -.051 & -.074 & -.030 & $-.157^{*}$ & 1 \\
\hline & Sig. (1-tailed) & .460 & .329 & .115 & .407 & .282 & .199 & .365 & .036 & \\
\hline & $\mathrm{N}$ & 132 & 132 & 132 & 132 & 132 & 132 & 132 & 132 & 132 \\
\hline
\end{tabular}

\subsection{Analysis of Variance- Regression Analyses}

Regarding the main objective of this study which is the identification of fundamental issues relevant to the implementation of EHR Med Rec in the Noor Hospital, analysis of variance (ANOVA)-Regression analyses with the standard method should be conducted. The fundamental reason that lies behind performing the mentioned statistical test is the elucidation of the overall relationship between nine mentioned issues as described earlier in tables 1 and 2 with EHR implementation Med Rec within the scope of this research as stated previously by author. Therefore, linear standard regression analysis was applied, which is a well-chosen and felicitous test to accomplish the primary objective of the current study.

Based on table 6, R and $\mathrm{R}$ square are equal with 1.000. These results reveal that the adjustment of the model, which is inclusive of nine predictors and one dependent variable to the collected data is perfect. In another sentence, the author can elicit that value of 1.000 for $\mathrm{R}$ square representing that the model is explaining $100 \%$ variance in the latent dependent variable, which is EHR Implementation. ANOVA table as depicted in table 7 for the whole set of nine issues and EHR implementation indicates that F-value is considerable and significant and the p-value is less than .05 and these two results could not be calculated by SPSS program because of the excellent fitting final model to data set as stated earlier by author. In the regression analysis with the selection of standard method, the most conspicuous table is the coefficient table. This expository table is relevant to representing standardized beta coefficient, $\mathrm{T}$ statistics or T-value, and $\mathrm{p}$-value. According to table $8, \mathrm{~T}$ statistic is robust due to the excellent fit of the model to the data set, and this sentence is also identical for p-value. For the further exposition of the standardized beta coefficient, it is notable to state that the higher standardized beta coefficient is indicating the most top prediction. As can be seen in table 8 , all nine issues have affirmative determination or relationship with EHR implementation that is a meaningful finding based on existing literature. The most top determination is related to DI of which has a result of .312, and then PEI of which has an effect of .271. Tables 6, 7, and 8 represent all expedient information. Supporting tables and figure have been appended.

Table 6. Model Summaryb

\begin{tabular}{|c|c|c|c|c|}
\hline Model & $\mathrm{R}$ & R Square & Adjusted R Square & Std. Error of the Estimate \\
\hline 1 & $1.000^{\mathrm{a}}$ & 1.000 & 1.000 & .00000 \\
\hline
\end{tabular}

Table 7. ANOVA ${ }^{\mathrm{a}}$

\begin{tabular}{ccccccc}
\hline & Model & Sum of Squares & df & Mean Square & F & Sig. \\
\hline 1 & Regression & 6.214 & 9 & .690 &. &. \\
& Residual & .000 & 122 & .000 & & \\
Total & 6.214 & 131 & & & \\
\hline
\end{tabular}

a. Dependent Variable: EHR Implementation

b. Predictors: (Constant), DI, CCI, WI, RI, PCI, OAI, ITRI, PEI, WTI 
Table 8. Coefficients ${ }^{\mathrm{a}}$

\begin{tabular}{|c|c|c|c|c|c|c|}
\hline & \multirow[b]{2}{*}{ Model } & \multicolumn{3}{|r|}{ Standardized } & & \multirow[b]{2}{*}{ Sig. } \\
\hline & & $\mathrm{B}$ & Std. Error & $\frac{\text { Coefficients }}{\text { Beta }}$ & $\mathrm{t}$ & \\
\hline \multirow[t]{10}{*}{1} & (Constant) & $-1.554 \mathrm{E}-15$ & .000 & & . & . \\
\hline & CCI & .111 & .000 & .206 & . & . \\
\hline & PEI & .111 & .000 & .271 & . & . \\
\hline & OAI & .111 & .000 & .229 & . & . \\
\hline & PCI & .111 & .000 & .199 & . & . \\
\hline & ITRI & .111 & .000 & .165 & . & . \\
\hline & WTI & .111 & .000 & .192 & . & . \\
\hline & WI & .111 & .000 & .237 & . & . \\
\hline & RI & .111 & .000 & .251 & . & . \\
\hline & DI & .111 & .000 & .312 & . & \\
\hline
\end{tabular}

\section{Discussion and Conclusion}

\subsection{Main Findings}

The fundamental premises behind the chief impetus of conducting the current study were to test the implementable model in the Noor hospital proposed by Rangachari et al. (2019). The next presupposition was an academic contribution to the healthcare industries in Iran of which have not implemented EHR in their hospitals. As described earlier, all issues had a positive relationship with EHR implementation. Therefore, with these achieved results; the author can deduce that superior role of EHR for enhancement and amelioration of patient outcomes and practitioners is undeniable.

\subsection{Managerial Ramifications}

This research insinuates important messages for managers in the healthcare industries through all over the world, especially Iran, as a developing country of which model used in this study can be practical and implementable in their industries. Therefore, it can be stated that the current research can be as a paradigm for managers in the healthcare industries. The most superior contribution of this research is its pragmatism and practicality in the Noor hospital in order to boost reconciliation of medication procedure to achieve a reliable and free of errors medication from admission to discharge. Moreover, bringing realization and insight due to advantageous and promising outcomes of EHR implementation for the amelioration of medication reconciliation from admission to discharge and supporting that this model has been implementable and pragmatic within the scope of this study. For further exemplification, working on DI and PEI to enhance the level of reliability of documentation matters and educating patients. Because these issues have had the most top ones among nine issues. It can be asserted that managers should take an essential strategy to improve EHR system and upgrading this system with identical systems in developed countries to gain sustainable merits. For the case of information technology issue, there is a need for erection of sound infrastructure, and it can be an appropriate strategy for managers in the healthcare industries. The acceleration of the medication procedure through EHR is significant for time management, data sustainability, storing and retrieving medication lists, reporting in a fast way, quality control, managerial monitoring of clinical activities, clinical outcomes, cost-effectiveness, and other hopeful outcomes as reviewed earlier in the literature review part of this scientific article. With these above salient points, it can be deduced that many benefits will be subsequent which are diminution of costs, global advantage inclusive of removing paper-based medication list, increasing Return on Investment (ROI), avoiding wasting time, increasing profitability, eluding stagnation that all mentioned points are felicitous way to have a thriving healthcare industry especially in hospitals.

\subsection{Limitations}

Regarding the nature of each research, the author coped with some restrictions while conducting it. The first remarkable one was relevant to the procedure of completion of data collection. Practitioners (respondents) were in the busy schedule despite their willingness to cooperate, especially ophthalmologists due to the nature of hospital that is a kind of service industry. Therefore, the author acted as a fieldworker and asked them important points verbally. The second limitation is the scope of the study. Noor hospital has two other branches in Tehran (the capital city of Iran). This research is exclusively limited to Noor hospital located in Alborz province. The third limitation is related to the survey instrument with the proper standard, which has been adapted from the recent study, as mentioned earlier. 


\subsection{Recommendations for Future Studies Development}

Apart from the limitations of the study, this research points out avenues for future studies in this research era, which are first: researches the same as the current one can be replicated in other hospitals of which have implemented EHR not only limited to Iran but also for other developing countries. Secondly, as mentioned earlier, this research was exclusively restricted to one branch of Noor hospital. Therefore, it is highly suggested to cover future study in the other two branches of Noor hospital located in Tehran in order to achieve a more comprehensive data from practitioners and analyzing data via Structural Equation Modeling (SEM) that is the analysis of covariance structure. Thirdly, determining a larger sample size more than two-hundreds is highly recommended to apply SEM technique for achievement of cogent and sound conclusions. Fourthly, investigation of more latent concepts related to EHR Med Rec will be a laudable accomplishment by scholars in future studies. Fifthly, academic achievement in future studies to explore mediator and moderator affecting EHR Med Rec is suggested by applying the pattern proposed by Baron and Kenny (1986). Sixthly, future researches can have a focus on group discussion and the users' perspectives as well. Finally, as recommended by Ndifon et al. (2016) addressing the framework of cyber-security with its continuous functions, which are: "Identification, Protect, Detect, Respond, and Recover."

\section{References}

Agency for Healthcare Research and Quality. (2016). Patient safety primer: medication reconciliation. Retrieved from https://psnet.ahrq.gov/primers/primer/1/medication-reconciliation

Ajami, S., Ketabi, S., Isfahani, S. S., \& Heidari, A. (2011). Readiness assessment of electronic health records implementation. Acta Informatica Medica, 19(4), 224. https://doi.org/10.5455/aim.2011.19.224-227

Aspden, P., Wolcott, J., Bootman, J. L., \& Cronenwett, L. R. (2007). Committee on identifying and preventing medication errors. Preventing medication errors: quality chasm series, 1269-1272.

Aspden, P., Wolcott, J. A., Bootman, J. L., \& Cronenwett, L. R. (2007). Preventing medication errors: National Acad. Press.

Barnsteiner, J. H. (2005). Medication Reconciliation: Transfer of medication information across settings-keeping it free from error. AJN The American Journal of Nursing, 105(3), 31-36. https://doi.org/10.1097/00000446-200503001-00007

Baron, R. M., \& Kenny, D. A. (1986). The moderator-mediator variable distinction in social psychological research: Conceptual, strategic, and statistical considerations. Journal of personality and social psychology, 51(6), 1173. https://doi.org/10.1037/0022-3514.51.6.1173

Bartlett, M. S. (1954). A note on the multiplying factors for various $\chi 2$ approximations. Journal of the Royal Statistical Society. Series B (Methodological), 296-298. https://doi.org/10.1111/j.2517-6161.1954.tb00174.x

Boonstra, A., Versluis, A., \& Vos, J. F. (2014). Implementing electronic health records in hospitals: a systematic literature review. BMC health services research, 14(1), 370. https://doi.org/10.1186/1472-6963-14-370

Borhani, F., Lashkari, T., Sabzevari, S., \& Abbaszadeh, A. (2013). Effect of telenursing (telephone follow-up) on glycemic control and body mass index (BMI) of type 2 diabetes patients. Iranian journal of nursing and midwifery research, 18(6), 451.

Burton, R. A. (2012). Health policy brief: improving care transitions.

Churchill Jr, G. A. (1979). A paradigm for developing better measures of marketing constructs. Journal of marketing research, 16(1), 64-73. https://doi.org/10.1177/002224377901600110

Coakes, S. J., \& Steed, L. (2009). SPSS: Analysis without anguish using SPSS version 14.0 for Windows: John Wiley \& Sons, Inc.

Coleman, E. A. (2003a). Falling Through the Cracks: Challenges and Opportunities for Improving Transitional Care for Persons with Continuing Complex Care Needs. Paper presented at the JAGS v: 51. https://doi.org/10.1046/j.1532-5415.2003.51185.x

Coleman, E. A. (2003b). Falling through the cracks: challenges and opportunities for improving transitional care for persons with continuous complex care needs. Journal of the American Geriatrics Society, 51(4), 549-555. https://doi.org/10.1046/j.1532-5415.2003.51185.x

Creswell, J. W. (2014). A concise introduction to mixed methods research: Sage Publications.

Cronbach, L. J. (1951). Coefficient alpha and the internal structure of tests. psychometrika, 16(3), 297-334. 
https://doi.org/10.1007/BF02310555

Darvish, A., \& Far, M. (2017). A review on implementation of electronic health in Iran literature. MOJ Womens Health, 5(5), 00136. https://doi.org/10.15406/mojwh.2017.05.00136

Farahani, R. H., Sharifi, M., Ayat, M., \& Moghaddam, N. M. (2014). Hospital Information Systems in Iranian Military Hospitals: A Multiple Case Analysis. Journal of Archives in Military Medicine, 2(4). https://doi.org/10.5812/jamm.22853

Field, A. (2005). Discovering statistics using SPSS . Thousand Oaks, CA, US: Sage Publications, Inc.

Gefen, D., Straub, D., \& Boudreau, M. C. (2000). Structural equation modeling and regression: Guidelines for research practice. Communications of the association for information systems, 4(1), 7. https://doi.org/10.17705/1CAIS.00407

Gonzalez, J. (2013). The Case for Electronic Health Records. Secure EDI. Retrieved from http://www.secureedi.com/documents/the_case_for_electronic_health_record.pdf

Greenwald, J. L., Halasyamani, L., Greene, J., LaCivita, C., Stucky, E., Benjamin, B., . . Williams, M. V. (2010). Making inpatient medication reconciliation patient centered, clinically relevant and implementable: a consensus statement on key principles and necessary first steps. Journal of Hospital Medicine, 5(8), 477-485. https://doi.org/10.1002/jhm.849

Grossman, J., Gourevitch, R., \& Cross, D. A. (2014). Hospital experiences using electronic health records to support medication reconciliation. Research Brief, 17.

Hair, J. F., Sarstedt, M., Ringle, C. M., \& Mena, J. A. (2012). An assessment of the use of partial least squares structural equation modeling in marketing research. Journal of the academy of marketing science, 40(3), 414-433. https://doi.org/10.1007/s11747-011-0261-6

Hekmat, S. N., Dehnavieh, R., Behmard, T., Khajehkazemi, R., Mehrolhassani, M. H., \& Poursheikhali, A. (2016). Evaluation of Hospital Information Systems in Iran: A Case Study in the Kerman Province. Global Journal of Health Science, 8(12), 95. https://doi.org/10.5539/gjhs.v8n12p95

Jahanbakhsh, M., Sharifi, M., \& Ayat, M. (2014). The status of hospital information systems in Iranian hospitals. Acta Informatica Medica, 22(4), 268. https://doi.org/10.5455/aim.2014.22.268-275

Kaiser, H. F. (1974). An index of factorial simplicity. psychometrika, 39(1), 31-36. https://doi.org/10.1007/BF02291575

Kline, R. B. (1998). Structural equation modeling: New York: Guilford Press.

Marmor, R. A., Clay, B., Millen, M., Savides, T. J., \& Longhurst, C. A. (2018). The impact of physician EHR usage on patient satisfaction. Applied clinical informatics, 9(01), 011-014. https://doi.org/10.1055/s-0037-1620263

Maslakpak, M. H., \& Safaie, M. (2016). A comparison between the effectiveness of short message service and reminder cards regarding medication adherence in patients with hypertension: a randomized controlled clinical trial. International journal of community based nursing and midwifery, 4(3), 209.

Mueller, S. K., Sponsler, K. C., Kripalani, S., \& Schnipper, J. L. (2012). Hospital-based medication reconciliation practices: a systematic review. Archives of internal medicine, 172(14), 1057-1069. https://doi.org/10.1001/archinternmed.2012.2246

Nasiripour, A. A., Rahmani, H., Radfar, R., \& Najafbeigi, R. (2012). Effective elements on e-health deployment in Iran. African Journal of Business Management, 6(16), 5543-5550. https://doi.org/10.5897/AJBM11.2791

Ndifon, L., Edwards, J. E., \& Halawi, L. (2016). Impact of Electronic Health Records On Patient Outcomes. Issues in Information Systems, 17(4), 187.

Nguyen, L., Bellucci, E., \& Nguyen, L. T. (2014). Electronic health records implementation: an evaluation of information system impact and contingency factors. International journal of medical informatics, 83(11), 779-796. https://doi.org/10.1016/j.ijmedinf.2014.06.011

Nunnally, J. (1978). Psychometric theory (2nd edit.) mcgraw-hill. Hillsdale, NJ, 416.

Nunnally, J., \& Bernstein, I. (1967). McGraw-Hill series in psychology. Psychometric theory. New York, NY, US: McGraw-Hill.

Peter, J. P. (1979). Reliability: A review of psychometric basics and recent marketing practices. Journal of 
marketing research, 16(1), 6-17. https://doi.org/10.1177/002224377901600102

Pronovost, P., Weast, B., Schwarz, M., Wyskiel, R. M., Prow, D., Milanovich, S. N., . . Lipsett, P. (2003). Medication reconciliation: a practical tool to reduce the risk of medication errors. Journal of critical care, 18(4), 201-205. https://doi.org/10.1016/j.jcrc.2003.10.001

Rangachari, P., Dellsperger, K. C., Fallaw, D., Davis, I., Sumner, M., Ray, W., . . Rethemeyer, R. K. (2019). A Mixed-Method Study of Practitioners' Perspectives on Issues Related to EHR Medication Reconciliation at a Health System. Quality Management in Healthcare, 28(2), 84-95. https://doi.org/10.1097/QMH.000000000000208

Salehahmadi, Z., \& Hajialiasghari, F. (2013). Telemedicine in Iran: chances and challenges. World journal of plastic surgery, 2(1), 18.

Triantafillou, P. (2017). Making electronic health records support quality management: A narrative review. International journal of medical informatics, 104, 105-119. https://doi.org/10.1016/j.ijmedinf.2017.03.003

Tubaishat, A. (2019). The effect of electronic health records on patient safety: A qualitative exploratory study. Informatics for Health and Social Care, 44(1), 79-91. https://doi.org/10.1080/17538157.2017.1398753

Vakili, M., Abedi, P., Afshari, P., \& Kaboli, N. E. (2015). The effect of mobile phone short messaging system on healthy food choices among Iranian postmenopausal women. Journal of mid-life health, 6(4), 154. https://doi.org/10.4103/0976-7800.172295

Versel, N. (2013). Health IT holds key to better care integration. Information Week website. Retrieved from http://www.informationweek.com/healthcare/interoperability/health-it-holds-key-to-better-care-integ/24001 2443

Zikmund, W., \& Babin, B. (2006). Exploring marketing research: Cengage Learning.

Zikmund, W., \& Babin, B. (2009). Essentials of Marketing Research (Book Only). South-Western Pubublication.

Zikmund, W. G., Babin, B. J., Carr, J. C., \& Griffin, M. (2013). Business research methods: Cengage Learning.

\section{Appendices}

\section{Scree Plot of Factor Analysis}

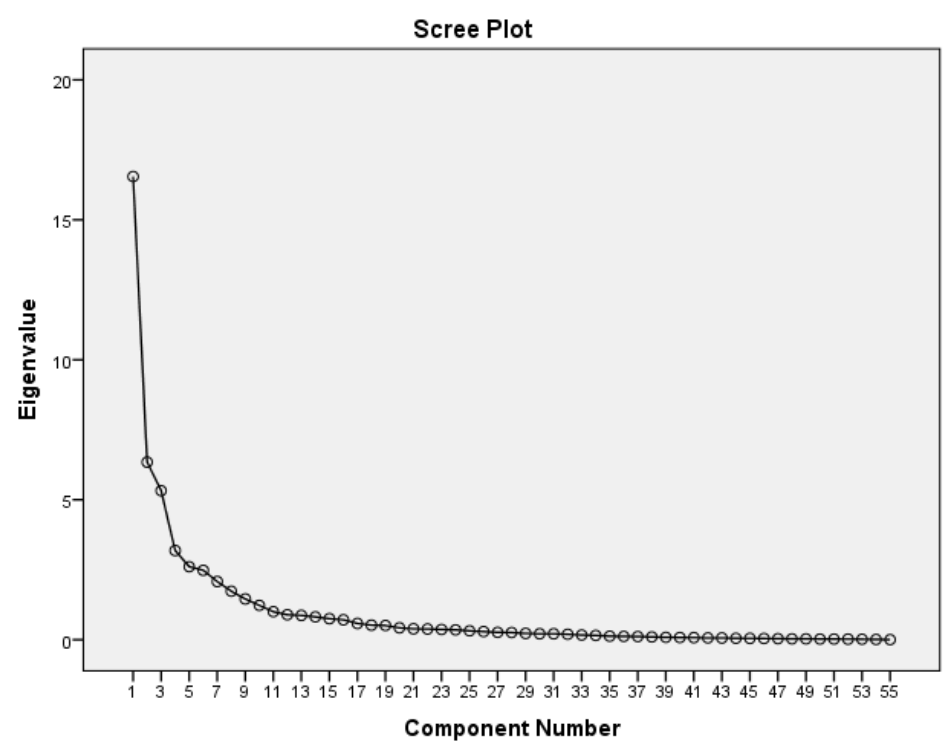




\begin{tabular}{cccc}
\hline & \multicolumn{3}{c}{ Descriptive Statistics of Latent Concepts } \\
\hline CCI & Mean & Std. Deviation & $\mathrm{N}$ \\
PEI & 4.7565 & .40357 & 132 \\
OAI & 4.5715 & .53210 & 132 \\
PCI & 4.6311 & .44792 & 132 \\
ITRI & 4.6098 & .39064 & 132 \\
WTI & 4.6035 & .32349 & 132 \\
WI & 4.6225 & .37628 & 132 \\
RI & 4.7500 & .46484 & 132 \\
DI & 4.5177 & .49134 & 132 \\
\end{tabular}

\begin{tabular}{|c|c|c|c|c|c|}
\hline \multicolumn{6}{|c|}{ Standard Regression Analysis Residuals Statistics ${ }^{\mathrm{a}}$} \\
\hline & Minimum & Maximum & Mean & Std. Deviation & $\mathrm{N}$ \\
\hline Predicted Value & 3.6951 & 4.9630 & 4.6294 & .21780 & 132 \\
\hline Std. Predicted Value & -4.290 & 1.531 & .000 & 1.000 & 132 \\
\hline Standard Error of Predicted Value & .000 & .000 & .000 & .000 & 132 \\
\hline Adjusted Predicted Value & 3.6951 & 4.9630 & 4.6294 & .21780 & 132 \\
\hline Residual & .00000 & .00000 & .00000 & .00000 & 132 \\
\hline Std. Residual & . & . & . & . & 0 \\
\hline Stud. Residual & . & 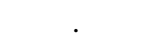 & 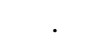 & . & 0 \\
\hline Deleted Residual & .00000 & .00000 & .00000 & .00000 & 132 \\
\hline Stud. Deleted Residual & . & & & 年 & 0 \\
\hline Mahal. Distance & 1.342 & 33.425 & 8.932 & 6.441 & 132 \\
\hline Cook's Distance & . & & & . & 0 \\
\hline Centered Leverage Value & .010 & .255 & .068 & .049 & 132 \\
\hline
\end{tabular}

\section{Copyrights}

Copyright for this article is retained by the author(s), with first publication rights granted to the journal.

This is an open-access article distributed under the terms and conditions of the Creative Commons Attribution license (http://creativecommons.org/licenses/by/4.0/). 